\title{
Comparative Study of Labor-Based Method and Machine-Based Method at Rural Road Construction and Maintenance in Jimma Zone, Oromia Region, Ethiopia
}

\author{
Anwar Kassahun Dunffa ${ }^{1}$, Emer Tucay Quezon ${ }^{2}$, Elmer De Castro Agon ${ }^{3}$ \\ ${ }^{1}$ Construction Engineering and Management, Faculty of Civil and Environmental Engineering, Jimma Institute of Technology, Jimma \\ University, Jimma, Ethiopia \\ ${ }^{2}$ Construction Engineering and Management Stream, Faculty of Civil and Environmental Engineering, Jimma Institute of Technology, Jimma \\ University, Jimma, Ethiopia \\ ${ }^{3}$ Faculty of Civil and Environmental Engineering, Jimma Institute of Technology, Jimma University, Jimma, Ethiopia
}

\section{Email address:}

anwarkassahun@yahoo.com (A. K. Dunffa), quezonet09@gmail.com (E. T. Quezon), quezonet09@yahoo.com (E. T. Quezon), elmer_c_agon@yahoo.com (E. De C. Agon)

\section{To cite this article:}

Anwar Kassahun Dunffa, Emer Tucay Quezon, Elmer De Castro Agon. Comparative Study of Labor-Based Method and Machine-Based Method at Rural Road Construction and Maintenance in Jimma Zone, Oromia Region, Ethiopia. American Journal of Civil Engineering. Vol. 5, No. 4, 2017, pp. 212-219. doi: 10.11648/j.ajce.20170504.13

Received: April 11, 2017; Accepted: April 20, 2017; Published: June 21, 2017

\begin{abstract}
The construction of physical infrastructure is contributory for poverty alleviation in every country. The road is one of the major components which is very significant in Ethiopia due to lack of highly developed infrastructure, particularly in the rural road sector. Selection of the appropriate road construction and maintenance methods such as labor-based method or machine-based method is necessary to be financially viable. Most rural road construction projects usually suffer from the problem of selecting the appropriate technology for the proposed project and implementation of the chosen technology. In Ethiopia, Universal Rural Road Access Program (URRAP) is an employment-intensive program for employment purpose as a first step, out of poverty using labor-based road construction. However, there are problems, constraints, and challenges encountered when implementing labor-based method leading to enforce the mobilization of machines. The aim of this research study is to carry out the comparative analysis of ongoing and finished rural road projects in Jimma Zone and to establish a qualitative and quantitative merit of various technologies used in rural road construction and maintenance. Results showed from financial cost comparison, the labor - based method was $47 \%$ cheaper than a machine-based method to carry out the same tasks. On the other hand, the share of unskilled average direct labor cost comprised of an astounding $65 \%$ more of the total direct cost of a labor-based method. Also, labor-based method directly employed 300 unskilled laborers per workday for a month to complete $1.0 \mathrm{~km}$ section of a rural road.
\end{abstract}

Keywords: Poverty Alleviation, Labor-Based and Machine-Based Methods, Rural Road Construction and Maintenance, Universal Rural Road Access Program (URRAP)

\section{Introduction}

The past commencements of Rural Roads Rehabilitation in Ethiopia traced back from the late 1970s onwards, and have been an important delivery mechanism for restoring access for the rural population to markets, social and other services to reduce transportation time and cost. Since the beginning of rehabilitating rural roads up to June 2010 different highway and road sector development programs were implemented using both labor-based and machine-based methods of rural road construction and maintenance to own a total of 127,328 kilometers of rural roads in Ethiopia.

Historically, implementation approach for construction and maintenance of rural road started since the actual commencement of rural road rehabilitation in Ethiopia. In 1980, the international labor organization (ILO) introduced labor-based approaches for the construction of roads to the Ethiopian Road Authority (ERA) and led the country to be the 
first in Africa to introduce labor-based mechanisms along with Kenya and Lesotho [1]. In Ethiopia, road transportation development plays a vital role in economic activity, poverty alleviation, employment creation and access to markets. Approximately 64 percent of the land area in Ethiopia lies more than 5 kilometers from an all-weather road. Some 48 million people in the rural areas of Ethiopia live further than 2 kilometers away from the nearest all-weather roads. On average, households are often more than 10 kilometers away from a dry-weather road, and 18 kilometers away from public transport services [2]. Road construction projects perceived as a means through which development strategies of the government are primarily intended to achieve by agricultural activities, investment projects and industrial development of the country. This scenario can only realize if there are adequate and efficient transportation networks available in every locality. In recognition of this crucial role of the road sector, various programs have been implemented to develop it. One of the programs that are being initiated by the government, specifically Ethiopian Road Authority (ERA) is the Road Sector Development Program Four (RSDP IV).

Most rural road construction and maintenance projects usually experience with the problem of selecting the appropriate technology for implementation of the road project and applying the chosen technology. In Ethiopia, the Universal Rural Road Access program (URRAP) is an employment intensive program of the government, and it will, where possible, used by the job as a first step out of the poverty of the local community by using labor-based road construction and maintenance [3].

However, the researcher perceives that challenges are confronting the actual implementation of the labor-based method and machine-based method. The research study would seek to determine the impacts and to comparisons between the use of labor-based and machine-based methods for the construction and maintenance of rural road projects. It will concentrate on the cost aspect to show how one of these methods work efficiently rather than the technical ones. This study, conducted by assessing the socioeconomic and financial impacts for one of low-income Regional States working for the development of economic activity, poverty reduction, employment creation and access to markets like in Jimma Zone.

The overall aim of the research study is to carry out the comparative analysis of ongoing and completed rural road projects in Jimma Zone and to establish qualitative and quantitative benefits of different technologies used in road construction and maintenance. To do this, the specific objectives are addressed: a) To set a financial cost comparison between the used of the Labor-based method and Machine-based method per kilometer length for the building and maintenance of rural road projects in Jimma Zone; b) To determine the impact of using the labor-based method and machine-based method for rural road construction and maintenance regarding socioeconomic cost; c) To show which labor force constitutes a more efficient in utilizing these two approaches for project implementation of rural road construction and maintenance; and d) To identify problems or constraints as well as challenges that will be encountered when using a labor-based method or machine-based method for Universal Rural Road Access Program (URRAP) and to come up with the corresponding scope of works to be done using the appropriate method.

In addition, the research study attempted to compare the labor-based method and machine-based method of rural road construction and maintenance in Jimma Zone. Furthermore, the research study sought to answer the following questions:

1. What type of rural road project that will be best suited for a financial cost comparison between the used of the labor-based method and machine-based method per kilometer length for construction and maintenance of the rural road in Jimma Zone?

2. What are the direct and indirect impacts of using labor-based method over the machine-based method for use in rural road construction and maintenance?

3. Which is more efficient to use labor force; labor-based method or equipment-based method?

4. What are the problems or constraints as well as challenges to be encountered when one of these two approaches used for implementation of rural road construction and maintenance?

\section{Research Methodology}

\subsection{Study Area}

From nine regional states and two city administrations assigned in the constitution of Ethiopia, all are implementing rural road construction and upgrading projects except the Capital City of Addis Ababa. Hence, the study is carried out at Jimma Zone from Oromia regional states of Ethiopia.

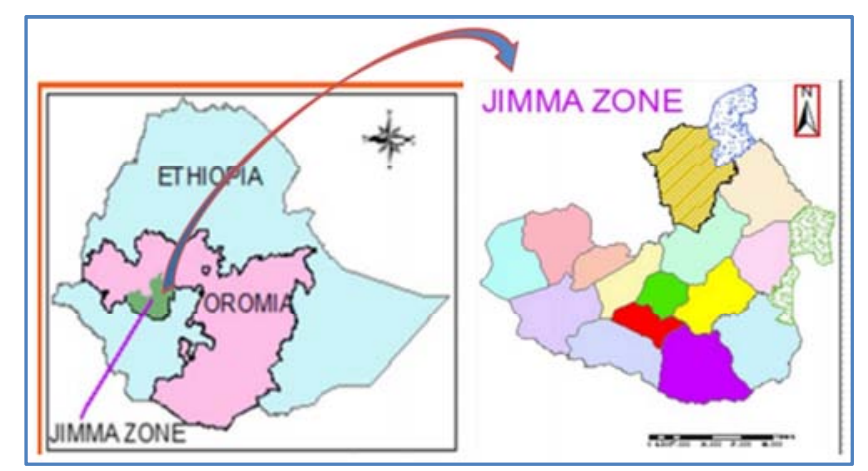

Figure 1. Map of the research study area (Source: Google map; 2016).

\subsection{Population of the Research Study}

The respondents of the survey include three parties, i.e. Client, Contractors and Consultants involved in the rehabilitation of rural road projects; and professionals who included in the URRAP program of Jimma zone. Currently, there are 29 established Contractors and eight established Consultants in all 17 Weredas participating in the rehabilitation of total target $2,260 \mathrm{~km}$ or 84 projects within five years' time (2011 to 2015). 


\subsection{Sampling Technique and Sample Size}

The objective of sampling is to provide a data collection and processing of the research to be carried out and ensuring that the samples provide a good representation of the population; i.e. The sample is representative. For complete information about the population of the survey, systematic sampling was used as the sampling technique of the research to extract the sample efficiently and to ensure each case spread across the population.

Table 1. Population of the study-All Weredas in Jimma Zone.

\begin{tabular}{llllllll}
\hline \multicolumn{2}{l}{ All 17 Wereda of Jimma Zone } & & & & & \\
\hline No & Wereda & No & Wereda & No & Wereda & No & Wereda \\
\hline 1 & Chora-Botor & 6 & Limu Kosa & 11 & Qarsa & 16 & Sokoru \\
2 & Dedo & 7 & Limu Saqa & 12 & Saqa Choqorsa & 17 & Xiro Afata \\
3 & Gera & 8 & Mana & 13 & Saxama & & \\
4 & Goma & 9 & Nono Benja & 14 & Shebe Sombo & & \\
5 & Gumayi & 10 & Omo Nada & 15 & Sigmo & & \\
\hline
\end{tabular}

The systematic sampling method used, wherein the following 5 Weredas extracted as a sample from a total 17 Weredas of Jimma zone.

Table 2. Sampled Weredas.

\begin{tabular}{lllll}
\hline \multicolumn{4}{l}{ Sample weredas } \\
\hline 1. Dedo & 2. Gumayi & 3. Mana & 4. Qarsa & 5. Shebe-Sombo \\
\hline
\end{tabular}

In this sample, 5 Weredas: 9 established contractor and four established consultant firms are engaged in 44 construction and maintenance, rural road projects for a total kilometer of 506.56 kilometers from 2011 to 2013 budget year, 36 projects or 409.56 kilometers completed, and eight projects or 92 kilometers are on-going. The established contractors and consultants constitute a General Manager, Material Engineer, Surveyor, and an additional Forman for the established contractor. While the clients also employ Engineers, Surveyors, and Technicians for the execution of these projects, hence all professionals of the three parties and projects in 5 Weredas are taken as a sample.

Table 3. All Projects at 5 Weredas.

\begin{tabular}{lllll}
\hline Wereda/Client & Contractor & Consultant & Projects & $\begin{array}{l}\text { Length } \\
(\mathbf{k m})\end{array}$ \\
\hline Total & 9 & 4 & 44 & 501.56 \\
\hline
\end{tabular}

\subsection{Research Strategy and Design}

Quantitative research strategy type followed since theoretical propositions developed for reviewing literature, observations, and experience of the researcher and inductive approach were used to provide a theory contribution through the initiated problems and explanation for variation in research questions as well. Two different methods for comparing the cost of road works by labor-based, and machine-based methods considered for this research study.

First, the cost of some similar projects carried out by labor-based and machine-based methods compared but the biggest problem with this comparing the means was the availability of sufficient projects conducted by the labor-based method and identifying sufficient appropriate data. This data makes the use of this kind of comparison deficient for cost comparison. For this reason, this method rejected from the study.

Second, to come up with a meaningful comparison with available data, the actual direct cost of carrying out average 1 kilometer of the project by the labor-based method can be compared with the cost of carrying out the same works by the equipment-based method, or vice versa. For this reason, this approach selected for this study.

\subsection{Research Study Approach}

To achieve the objectives of the research study and adequately answer the research questions, information gathered through a review of the literature, questionnaire, site observation, and reviewing the project's archival documents of projects in general. The study attended through the following phases of research approach:

(a) In phase one: The literature review carried out mainly to examine and understand the concept, the problem associated and the methodologies used from previous studies on comparative studies of labor-based and machine-based methods on rural road construction and maintenance. After an extensive literature review, standard formats used for data collection cost comparison and questionnaires organized to form which it distributed to three parties (clients, consultants, and contractors) involved in rural road construction and maintenance. The second and third phase includes the collection of data based on both desk review and field work.

(b) Desk review: Data collection started by collecting quantities (volume) of work executed from the bill of quantity of payments for completed and on-going rural road projects, while the completed projects have a finalized, actual amount of work, on-going projects have constraints for the remaining or total estimated quantities of works. The type and standard requirement are needed to execute activities using labor-based and machine-based methods. These are direct hiring, hand tools, equipment, and machinery collected from payrolls, reports, agreements and documents based on their mode of recruitment, and also each of productivity rates per standard units per hour or day are collected from ERA construction management systems: Construction performance standard and URRAP break down productivity rates.

(c) Field data collection:the structured questionnaire based 
on giving ranking approach from the respondents for the problem or constraints as well as challenges encountered when using the labor-based method or machine-based method for URRAP and also the corresponding scope of works to be done using the appropriate method. The respondents rated an entire list of 67 possible problems, constraints, challenges and 30 possible scopes of work to be done using the right method for both approaches in general.

(d) In the fourth phase, the data and information that collected in previous stages analyzed to make direct cost comparisons per kilometer using the two methods and identify the most ranked problems, constraints, challenges, and scope of work to be done using the appropriate method.

(e) Finally, the findings also analyzed about the objectives of the study and synthesized in the recommendations, including the possible solutions, suggestions as well were given based on results.

\subsection{Data Processing and Analysis}

Based on the data available and the output required from the research; descriptive statistics were employed to process and analyze the data using computer programs through Microsoft Excel and Statistical Package for the Social Sciences (SPSS).

\subsubsection{Direct Cost per Kilometer}

Direct cost per kilometer are those costs which are associated directly and unambiguously with the product or activity in question. It encompasses the direct cost of material (including transportation), labor and equipment used to produce an average one kilometer of rural road in the Jimma zone using the two methods.

In establishing a financial cost comparison, the average quantities (volumes) of work per kilometer determined by summarizing the projects collected numbers and dividing it to the total kilometer of the projects. The direct unit costs of each of the work items for labor-based and machine-based methods calculated in standard Microsoft Excel sheet based on their standard unit of measurement. Finally, the quantities and the direct unit costs are brought together to produce the actual direct costs of one kilometer by both methods.

KAPSEL (May 2004) explains the model parameters in the comparative study on the impact of labor-based methods in road works in Tanzania through sub-topics including economic cost comparison, the estimation of the employment creation and implication for poverty reduction [4].

\subsubsection{Economic Cost Comparison}

The economic analysis calculated from the viewpoint of the entire society. It answers the question: Is the project profitability to the organization or a target population as a whole? What is its impact (regarding job creation and linkages with the other sectors) on the overall economy?

\subsubsection{Estimation of the Employment Creation}

The employment creation is one among many variables, which could explain the effects of investment in the rehabilitation of feeder roads by employing LBT and EBT approaches. It computed by dividing total output by labor productivity ratio and the number of working days per annum.

\subsubsection{Implications for Poverty Reduction}

Poverty alleviation addressed through job creation in the respective communities. However, through their impacts on GDP, government revenue, and employment it is clear that LBT is more consistent with pro-poor growth, which is expected to have the greatest impact on poverty reduction and raising the standards of living of the rural communities and households.

\subsubsection{Relative Importance Index}

The Relative Importance Index (RII) was used to rank the different problems or constraints as well as challenges encountered and the different scope of work to be done using the appropriate methods. It made possible to cross-compare the most relative severity and importance from the list as perceived by the three groups of respondents (i.e. Clients, consultants, and contractors) perceptions for ranking relatively the factors. The Relative Importance Index is computed [5].

$$
\mathrm{RII}=\frac{\Sigma W}{N * A}
$$

Where:

$\mathrm{W}=$ weighting given to each case in a list by the respondents (ranging from 1 to 4 )

$\mathrm{A}=$ the highest weight provided ( 4 in this case)

$\mathrm{N}=$ total number of those surveyed (44 in this case)

\section{Results and Discussion}

This part of the study addresses and discusses the findings from analysis of the cost comparison and problem identification with the corresponding scope of work to be done when using one of the two methods. Financial and socioeconomic cost comparison resulted from 5 sampled Weredas which extracted from a total population size of 17 Weredas in Jimma zone. A total of 44 projects or a total of $501.56 \mathrm{~km}$ was analyzed, and a total population assumed in these five sampled Weredas.

\subsection{Response Rate}

The structured questionnaires distributed towards zone and Wereda level client, consultants and contractors from which a total of 44 responses used for a total of 51 . The estimated response rate indicated $86.27 \%$, and these respondents include professionals who are working as Project Coordinator, General Managers, Material engineers, Forman's and Surveyors and Technician in their job title with educational status from diploma to master's degree level. 
Table 4. Questionnaires Distributed and Response Rate.

\begin{tabular}{llllll}
\hline \multirow{2}{*}{ Respondents } & \multicolumn{4}{l}{ Questionnaires Distributed } & \multicolumn{2}{l}{ Questionnaires Returned } & Response Rate in (\%) \\
\cline { 2 - 6 } & In No. & In (\%) & In No. & 11.76 & 85.71 \\
1. Client & 7 & 13.73 & 6 & 17.65 & 81.82 \\
2. Consultants & 11 & 21.57 & 9 & 56.86 & 87.88 \\
3. Contractors & 33 & 64.71 & 29 & 86.27 & 86.27 \\
Total & 51 & 100 & 44 & & \\
\hline
\end{tabular}

The above table shows all the population at sampled Weredas which satisfactorily responded from the three parties.However, there were substantial difficulties to overcome the distribution and collection of the questionnaires.

\subsection{Financial Cost Comparison}

The overall average cost per kilometer for similar road construction and maintenance using labor-based method compared to the machine-based method was $47 \%$ cheaper in financial terms.

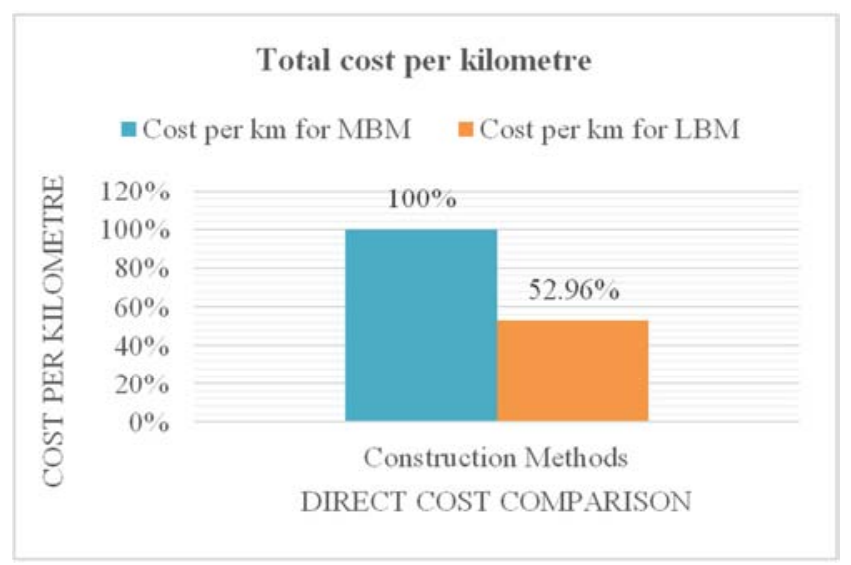

Figure 2. Cost Comparison per Kilometer between LBM \& MBM.

Based on the average project costs for every 1 kilometers built using a machine-based method, 1.9 kilometers could be constructed using a labor-based method.

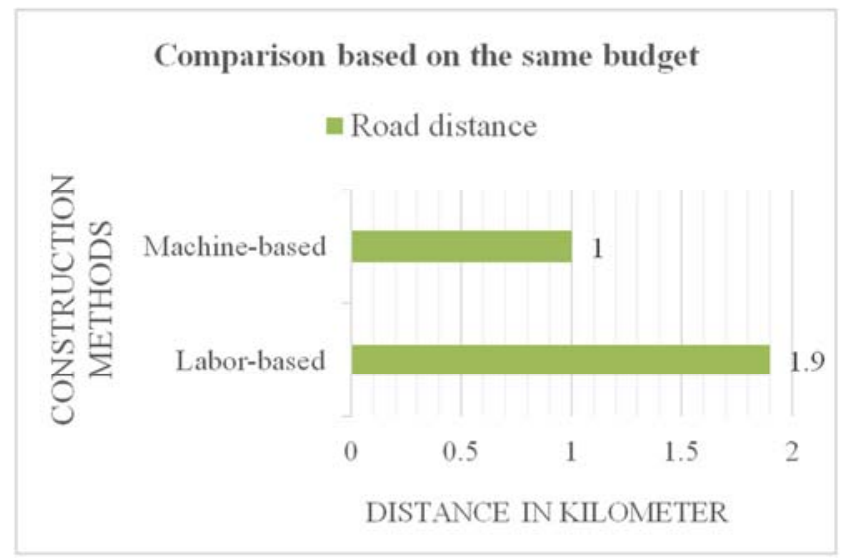

Figure 3. Cost Comparison based on the same Budget between LBM and $M B M$.

A rural road project used the machine-based method in construction and maintenance in the Jimma zone, was best suited for the financial cost comparison for the labor-based method because of its compiled activities of work in one item. Due to its simple analysis of direct unit cost and its small amount of laborers and equipment utilized to produce a particular event.

Average direct cost per kilometer for similar rural road construction and maintenance using labor-based method revealed that $47 \%$ cheaper in financial terms. These results, based on the average financial direct costs for every 1 kilometers built using a machine-based method, an equivalent 1.9 kilometers constructed using the labor-based method.

\subsection{Socioeconomic Cost}

The socioeconomic value represented by the share of average unskilled direct labor cost. It has an incredible $65.97 \%$ of the total average cost per kilometer of the labor-based method, while the machine-based method comprised of about $1 \%$. This figure showed a significant discrepancy when compared with the labor-based method.

Also, the labor-based method directly employed more than 300 unskilled laborers per month to produce an average 1-kilometer section of rural road.

On the other hand, the share of average Machinery direct cost was $60.29 \%$, and $32.18 \%$ of the direct cost goes to fuel for machine-based rural road construction and maintenance. While, the share of standard equipment, hand tools, and fuel direct cost was $22 \%$ of labor-based road building and maintenance.

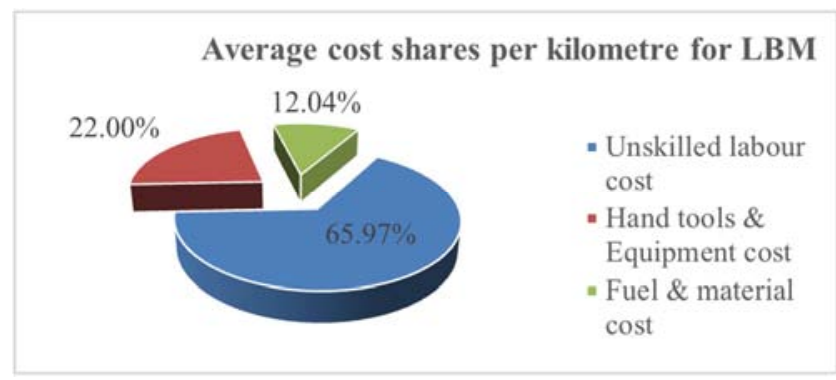

Figure 4. Average Cost Shares per Kilometer.

Average cost shares per kilometre for MBM

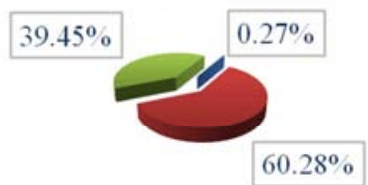

- Unskilled labor cost = Machinery cost

Fuel \& material cost

Figure 5. Average Cost Shares per Kilometer.

From the above results, it demonstrated that the labor-based 
method was more efficient when using a labor force for project implementation of rural road construction and maintenance.

Using labor-based method was relatively cheap in financial terms, creates more employment, an inflow of cash to the local community than over machine-based method. The resulted direct impacts from the labor-based method for rural road construction and maintenance would indirectly transfer knowledge about road construction, improved living standard among rural households, creates own sense at local communities, decreases rural to urban migration and poverty alleviation over machine-based method.

\subsection{Identification of Problems, Constraints and Challenges Encountered to Implement Labor-Based and Machine-Based Methods in Jimma Zone for URRAP}

The identification of the most problems, constraints, and challenges faced based on their degree of severity are presented, according to their category relation including contractor, client, and consultant related to both labor and machine-based methods. The same fashion is followed to offer the most, identify the scope of work to be done with the appropriate method on their relative importance.

Table 5. High Ranked Problems, Constraints and Challenges.

\begin{tabular}{|c|c|c|c|}
\hline Respondents & Rank & Problems, limitations, and challenges encountered & RII (\%) \\
\hline \multirow{7}{*}{ Contractors } & \multicolumn{3}{|c|}{ 1. Labor-based method } \\
\hline & 1 & Difficulty in mobilizing labor & 86.93 \\
\hline & \multicolumn{3}{|c|}{ 2. Machine-based method } \\
\hline & 1 & Cash required to mobilize machines at the beginning & 91.48 \\
\hline & 2 & Fuel consumption and cost & 87.50 \\
\hline & 3 & Too much rental cost of machinery & 82.95 \\
\hline & 4 & Fuel availability & 82.39 \\
\hline \multirow{7}{*}{ Client } & 1 & Budget or payment constraints & 92.05 \\
\hline & 2 & Lack of continuous training given time to time on Labor-based method & 88.07 \\
\hline & 3 & Insufficient funding & 81.25 \\
\hline & 4 & Delays in payments & 80.68 \\
\hline & 5 & Performance of supply equipment by government to supplement LBM against the requirement of standards & 80.11 \\
\hline & \multicolumn{3}{|c|}{ 2. Machine-based method } \\
\hline & & Delays in payments & 88.07 \\
\hline \multirow{3}{*}{ Consultants } & 1 & Delays in payments & 85.23 \\
\hline & \multicolumn{3}{|c|}{ 2. Machine-based method } \\
\hline & 1 & Delays in payments \& inspection & 82.95 \\
\hline
\end{tabular}

Table 5 shows the high ranked problems, constraints, and challenges identified based on the highly rated degree of severity when using a labor-based method. These were budget or payment constraints with Relative Importance Index of $92.05 \%$ under the client, difficulty in mobilizing labor with Relative Importance Index of $86.93 \%$ under the contractors, and delay in payments with Relative Importance Index of $85.23 \%$ under the consultants.

Also, the highest ranked problems, constraints, and challenges identified based on the highly rated degree of severity when using a Machine-based method. These are the Cash required to mobilize machines at the beginning with Relative Importance Index of $91.48 \%$ under the contractors, and Delays in payments with Relative Importance Index of
$88.07 \%$ under the client. Again, a delay on payments and inspection with Relative Importance Index of $82.95 \%$ revealed under the consultants.

\subsection{Identification of the Corresponding Scope of Works to Be Done by Using Labor-Based and Machine-Based Methods in Jimma Zone for Urrap}

Table 6 indicates the results of the high ranked corresponding scope of works to be done as identified based on high rated relative importance index when using a labor-based method and machine-based method as perceived by the three groups of respondents.

Table 6. High Ranked the Corresponding Scope of Works to be done.

\begin{tabular}{|c|c|c|c|}
\hline Respondents & Rank & The corresponding scope of works to be done & $\begin{array}{l}\text { RII } \\
(\%)\end{array}$ \\
\hline \multirow{5}{*}{ Contractor } & \multicolumn{3}{|c|}{ 1. Labor-based method } \\
\hline & 1 & $\begin{array}{l}\text { Training must be provided to professionals at the beginning, as well as regular undertakings until sufficient } \\
\text { knowledge obtained about an implementation of LBM. }\end{array}$ & 89.20 \\
\hline & 2 & $\begin{array}{l}\text { Contractors need to have enough knowledge about LBM before making agreements to have flexible management } \\
\text { systems that give due consideration to the awareness, culture, tradition and other factors. }\end{array}$ & 87.50 \\
\hline & 3 & $\begin{array}{l}\text { The contract document shall be prepared for both LBM \& MBM individually for proposed locations of projects to } \\
\text { pre-consider the nature of the project area which includes the availability of labor, wage rate for unskilled labor, the } \\
\text { productivity of labor, the supply of machines \& the character of the works to be executed. }\end{array}$ & 86.93 \\
\hline & \multicolumn{3}{|c|}{ 2. Machine-based method } \\
\hline
\end{tabular}




\begin{tabular}{|c|c|c|c|}
\hline Respondents & Rank & The corresponding scope of works to be done & $\begin{array}{l}\text { RII } \\
(\%)\end{array}$ \\
\hline \multirow{6}{*}{ Consultants } & 1 & $\begin{array}{l}\text { The labor-based program, a machine based program should be initiated to have a flexible choice of technology } \\
\text { practical for the proposed locations of the project. }\end{array}$ & 89.20 \\
\hline & 2 & $\begin{array}{l}\text { Priorities must be given to the implementation of LBM in locations where it is feasible to use, which helps in } \\
\text { avoiding too much fuel consumptions, the burden of mechanical failures, the cash required to mobilize machines at } \\
\text { the beginning, transportation cost of machinery and access to project areas. }\end{array}$ & 86.93 \\
\hline & \multicolumn{2}{|r|}{ 1. Labor-based method } & \\
\hline & 1 & $\begin{array}{l}\text { Training must be provided to professionals at the beginning, as well as regular undertakings until sufficient } \\
\text { knowledge obtained about an implementation of LBM. }\end{array}$ & 97.73 \\
\hline & \multicolumn{2}{|r|}{ 2. Machine-based method } & \\
\hline & 1 & $\begin{array}{l}\text { Totally avoid waiting's to certify payments to contractors on completing activities to secure safe cash flows and fees } \\
\text { for laborers on time. }\end{array}$ & 93.18 \\
\hline \multirow{7}{*}{ Client } & \multicolumn{2}{|r|}{ 1. Labor-based method } & \\
\hline & 1 & $\begin{array}{l}\text { The pre-technological study should be made in different locations of the country to be feasible before selection of } \\
\text { methodology to be implemented. }\end{array}$ & 97.73 \\
\hline & 2 & To meet the target of LBM sufficient funding/budget must be on hand ahead of beginning projects. & 89.77 \\
\hline & 3 & $\begin{array}{l}\text { Projects need to be handed over on time in the program budget year to avoid overlapping of last year project of this } \\
\text { year and to use the safest climatic condition for road works. }\end{array}$ & 87.50 \\
\hline & \multicolumn{2}{|r|}{ 2. Machine-based method } & \\
\hline & 1 & $\begin{array}{l}\text { Projects need to be handed over on time in the program budget year to avoid overlapping of last year project of this } \\
\text { year and also to use the safest climatic condition for road works. }\end{array}$ & 87.50 \\
\hline & 2 & $\begin{array}{l}\text { Sufficient study needs to be done on the availability of the required materials for the possible shortest distance to be } \\
\text { cost efficient and look for additional options like stabilization of the nearest available materials with chemicals to } \\
\text { fulfill the required standards. }\end{array}$ & 81.25 \\
\hline
\end{tabular}

The highest Relative Importance Index of $97.73 \%$ of the labor-based method under the client, showed that there is a need for the pre-technological study to be undertaken for different locations of the country before selecting the methodology to be implemented. In a similar manner, under the consultant's point of view concerning the labor-based method, training must be provided to professionals at the beginning, as well as regular undertakings until sufficient knowledge obtained about an implementation of LBM with Relative Importance Index of $97.73 \%$. The same factor mentioned, rated with $89.20 \%$ Relative Importance Index from the contractor.

The highest-ranked corresponding scope of works to be done based on high ranked Relative Importance Index when using the Machine-based method which entirely avoids waiting time to certify payments to contractors on completing activities to secure safe cash flows and fees for laborers on time with Relative Importance Index of $93.18 \%$ under the consultants. Likewise, under the contract for the labor-based program and a machine-based program should be initiated to have a flexible choice of technology practical for the proposed locations of the project with Relative Importance Index of $89.20 \%$. The client responded that projects need to be hands on time in a program budget year to avoid overlapping of the previous project. Also to use the safest climatic condition for road works with Relative Importance Index of $87.50 \%$.

\section{Conclusion}

Based on the findings of this research study, using the labor-based method is cheaper in financial terms per average kilometer than using the machine-based method. The labor-based method can generate more employment in the community living nearby in the project area. Following from these direct impacts of the labor-based method, rural road construction and maintenance are indirectly transferred knowledge about road construction methods and techniques, improved living standard among rural households, creates own sense at local communities, decreases rural to urban migration and poverty alleviation over machine-based method.

The share of unskilled average direct labor cost was an incredible $66 \%$ of the average direct cost per kilometer of a labor-based method, while only $1 \%$ for the machine-based method. The labor-based method directly employs more than 300 unskilled laborers per workday for a month in producing an average 1-kilometer section of a rural road project. All of these results demonstrated the labor-based method is more viable when using a labor force for project implementation of rural road construction and maintenance.

The research study identified the main problems or constraints related to both labor and machine-based methods during the implementation phase, which are budget constraints, delay of payments and inspection commonly from clients and consultants. While the challenges encountered by the contractors are a difficulty of mobilizing labor and cash required to mobilize machines at the beginning of the project for labor and machine-based methods, respectively.

\section{Recommendation}

The following recommendations are forwarded on the corresponding scope of work to be done using the methodologies as follows:

General:

a. The pre-technological study should be made in different 
locations of the country to be feasible before selection of the method to be implemented. Sufficient research needs to be done on the availability of the required materials for the possible shortest distance to be cost efficient and look for additional options like stabilization of the nearest available materials with chemicals to fulfill the required standards.

b. Projects need to be hands on time in the program budget year to avoid overlapping of the previous year's project and to use the safest climatic condition for road works.

c. Avoid long waiting time to certify payments due to contractors on completing works to secure reliable cash flows and fees for laborers on time.

For Labor-Based:

a. To meet the target of LBM, sufficient funding allocation must be on hand ahead of the beginning of projects.

b. Training must be given to professionals as well as the local community to obtain sufficient knowledge about the implementation of LBM.

c. Contractors need to have enough knowledge about LBM before making contract agreements with the client to have flexible management systems that give due consideration to the awareness, culture, tradition and other factors affecting the smooth flow of project works.

For Machine-Based Method:

a. The machine-based program should be initiated to have a flexible choice of technology useful for the proposed location of the project.

b. Priorities must be given to the implementation of LBM in places where it is feasible to use. It will help the contractor to avoid too much fuel consumptions, the burden of mechanical failures, the cash required to mobilize machines at the beginning, and transportation cost of machinery to access project areas.

\section{References}

[1] ILO (June 2008); Comparative Study of the Impact of Labor-Based and Equipment-Based Methods in Road works in Ethiopia - Study Rural Roads Authorities in Tigray and Amhara Regions in collaboration with the International Labor Organization.

[2] Ashong, k. (1994); Labor-Based Road Construction Projects, Summary of Activities and Progress. Ministry of Roads and Highways, Department of Feeder Roads, Accra.

[3] Ethiopian Road Authority (2011); Revised Universal Rural Road Access Program, Addis Ababa.

[4] K \& Associates Professional Services in Collaboration with Daima Associates Limited (May 2004); Comparative Study On the Impact Of Labor-Based And Equipment-Based Methods In Road Works In Tanzania.

[5] Cheung et al., (2004); Iyer and Jha, (2005); Ugwu and Haupt, (2007).

[6] Elisabeth, A. S. \& Jan, D. V. (October 1996); Expanding Labor-Based Methods for Road Works in Africa.

[7] Gary, T. (27 July 1998); Cost Comparison between Labor-Based and Equipment-Based Methods for Roadwork's: A Case Study from Ghana.

[8] John, V. R. (2005); Labor-Based Roadwork's: In development.

[9] Melese Mengistu, Prof. Emer T. Quezon, Getachew Kebede, (2016); Assessment of Factors Affecting Labor Productivity on Road Construction Projects in Oromia Region, Bale Zone, IJSER, Vol 7, Issue 11, pages 899-910.

[10] Grebehewit Girmay, (July 1994); Rural Roads Development in Ethiopia.

[11] Ahmed Atef Gaddalah, (TRB 2012); Assessment of Labor Based Construction Methods in Egyptian Rural Roads.

[12] Paul Munters, (2003); "Jobs or Machine", International Labour Office, ILO, Geneva. 